
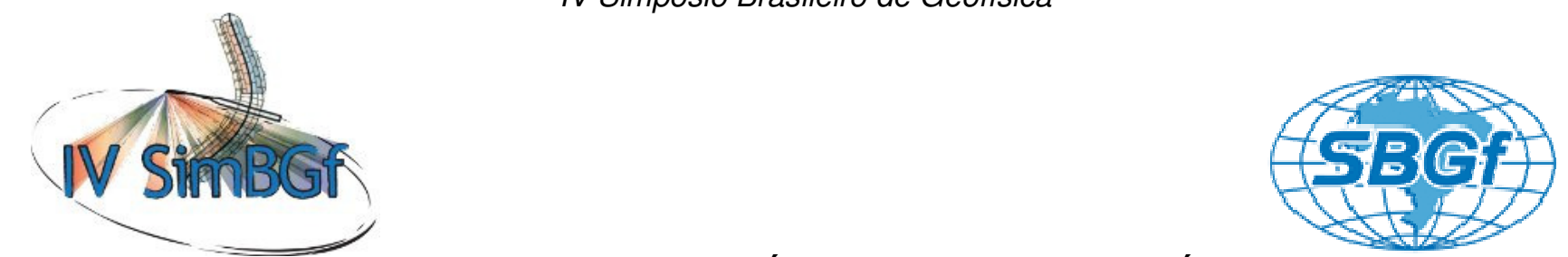

\title{
INVESTIGACAO PRELIMINAR COM OS MÉTODOS GPR E MAGNÉTICO DE URNAS FUNERÁRIAS DO SÍTIO NOSSA SRA. DO PERPÉTUO SOCORRO (PARÁ)
}

Eric Sandro Ferreira da Silveira* ${ }^{* 1}\left(\right.$ UFPA), Lúcia Maria da Costa e Silva ${ }^{2}$ (UFPA), Gustavo Nogueira ${ }^{3}$ (UFPA), Diogenes Leão Brasil $^{4}($ UFPA)

Copyright 2010, SBGf - Sociedade Brasileira de Geofísica

Este texto foi preparado para a apresentação no IV Simpósio Brasileiro de Geofísica, Brasília, 14 a 17 de novembro de 2010. Seu conteúdo foi revisado pelo Comitê Técnico do IV SimBGf, mas não necessariamente representa a opinião da SBGf ou de seus associados. É proibida a reprodução total ou parcial deste material para propósitos comerciais sem prévia autorização da SBGf.

\section{Resumo}

Este trabalho apresenta os resultados da aplicação e eficiência de métodos geofísicos na previsão de áreas potenciais para salvamento arqueológico no Sítio Nossa Senhora do Perpétuo Socorro no estado do Pará.

Os métodos utilizados foram Magnetometria e Radar de Penetração no Solo (GPR). As medidas magnéticas foram utilizadas para indicar os locais para escavação. $O$ GPR foi usado para confirmar as anomalias detectadas pelas medidas magnéticas e proporcionar uma melhor avaliação diminuindo os erros cometidos quando se identificam anomalias magnéticas que não são causadas por feições arqueológicas.

Para isso selecionou-se uma área menor ( $4 \times 4 \mathrm{~m})$ o qual se conhece perfeitamente a posição das urnas devido as mesmas estarem aflorando, a partir desses dados um padrão de respostas será utilizado em terrenos bem maiores no qual as urnas podem ou não estarem aflorantes.

\section{Introdução}

Durante o projeto Programa de identificação e salvamento do patrimônio arqueológico das rodovias BR163 e 230 em 2009, chegou ao conhecimento da equipe de Arqueologia do Laboratório de Antropologia Arthur Napoleão Figueiredo (LAANF) da Universidade Federal do Pará (UFPA). Foi identificado bordas de vasilhas cerâmicas aflorando em superfície, da chácara Nossa Senhora do perpétuo Socorro, situado sob as

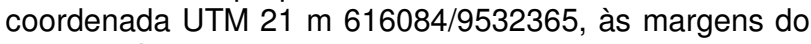
rio Tapajós, elevando-se $20 \mathrm{~m}$ acima do canal Piracanã, onde a equipe encontrou restos aflorantes de um grande número de urnas, mas removidas apenas treze delas.

O material removido ainda não foi estudado, de modo que a sua idade ainda é desconhecida, mas suas características permitem inferir que se tratam de urnas funerárias de enterramento (com dimensões variando de 20 a $75 \mathrm{~cm}$ ). Tamanha a abundância de material arqueológico, já permitem, contudo, afirmar que se trata de um dos maiores cemitérios arqueológicos descobertos na Amazônia.

As descobertas feitas a partir exclusivamente de indicações superficiais geradas pela ação antrópica (limpeza da propriedade) e pela alta pluviosidade trabalhando no relevo positivo, mostraram a necessidade de dar continuidade aos trabalhos bem como o uso da Geofísica para auxiliar na investigação subsuperficial.

Os primeiros trabalhos de prospecção geofísica aplicada à arqueologia na Amazônia que se têm registro foram realizados em 1977 no Sítio Teso dos Bichos, na llha de Marajó (ALVES, 1979; Alves \& LOURENÇO, 1981) foi realizado com Magnetometria e Eletrorresistividade (métodos clássicos consagrados para o estudo arqueológico). E somente em 1983 foi utilizado pela primeira vez no Brasil o método GPR (ground penetration radar) para investigação arqueológica (ROOSEVELT, 1991), cuja popularização na região se deu na década seguinte (Melo 2007, Aragão 2006, LUIZ 2010 A, Luiz 2006, Pereira 2004, Luiz 2004, Luiz 2003, Luiz 2010 B, Luiz 2009 e outros)

O presente trabalho optou por unir o novo ao clássico através do uso da Magnetometria e do GPR de modo que ambigüidades nos resultados obtidos com um método possam ser suprimidas por indicações obtidas com 0 outro método, a fim de se localizar locais propícios para novas descobertas, sem indicações superficiais.

\section{Localização e acesso}

O sítio arqueológico Nossa Senhora do Perpétuo Socorro está localizado no Oeste do estado do Pará próximo a fronteira com o Amazonas, no município de Itaituba. O acesso até a cidade de Itaituba é feito pela Rodovia Federal BR 230; estradas vicinais permitem alcançar o rio Tapajós em direção noroeste, a partir desse ponto de barco, chega-se ao sítio, às margens do rio Tapajós em um morro de topo plano a noroeste (figura 1). 
Sítio arqueológico Nossa Sra. do Perpétuo Socorro (Pará)

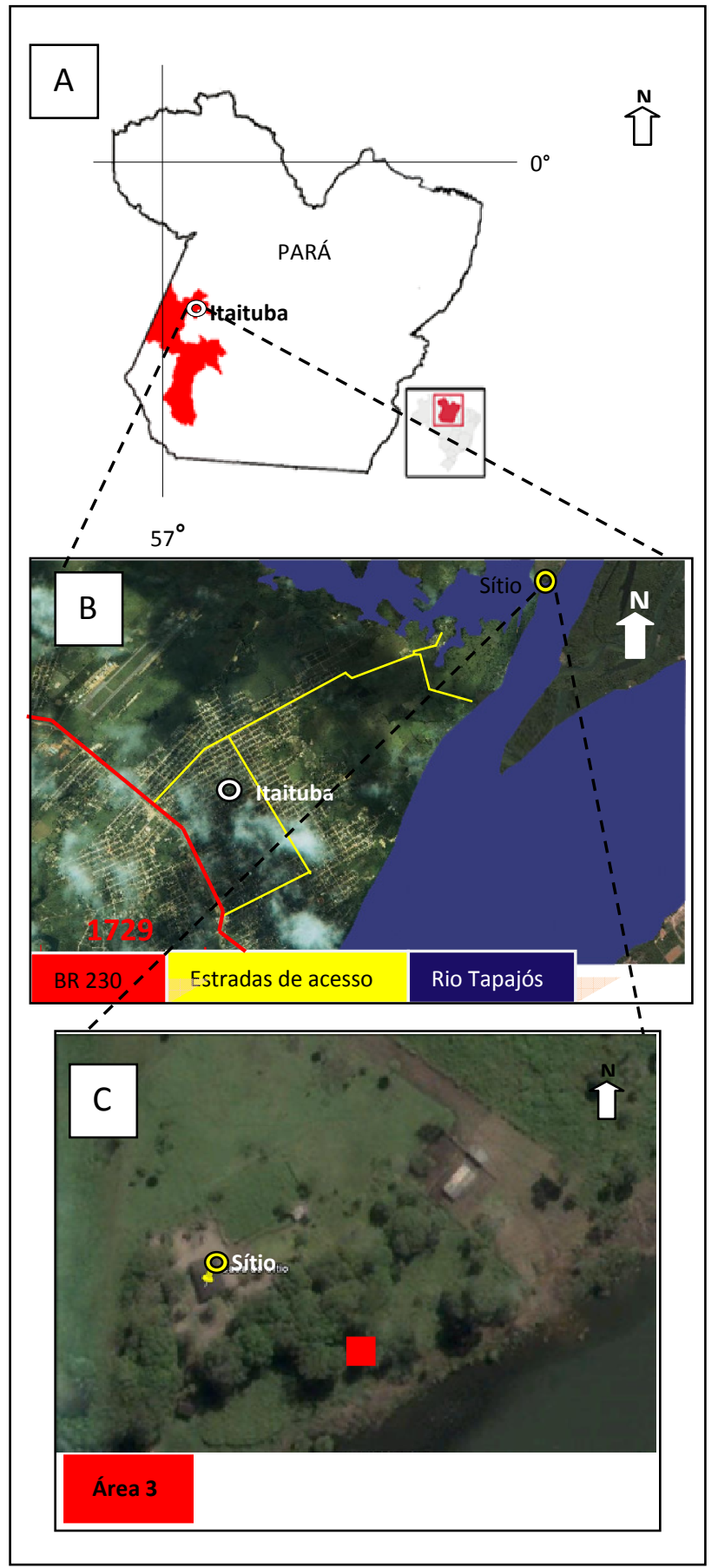

Figura 1- A: Localização do município de Itaituba (em vermelho) dentro do Estado do Pará; B: Estradas de acesso às proximidades do sítio dentro de Itaituba ; $C$ : Foto Aérea do sitio com ênfase na área 3.

\section{Geologia}

$\mathrm{Na}$ avaliação de horizontes litológicos, a escavação foi feita até 1 metro de profundidade para melhor compreenção da gradação. Ao todo foram avaliados 3 possiveis horizontes denominados respectivamente de $\mathrm{A}, \mathrm{B}$ e $\mathrm{C}$. O horizonte $\mathrm{A}$ corresponde a um sedimento areno argiloso fino mal selecionado, subarredondado, seleção pobre a moderada, quase completamente composto por quartzo, a cor é escura devido a presença de humus, possui profundidade de aproximadamente $30 \mathrm{~cm}$. O horizonte B corresponde a um sedimento areno argiloso moderadamente selecionado. Sua maior concentração é de quartzo com altas concentração de minusculas concreções de ferro, a cor apesar de escura tende ao amarelado, este horizonte segue até $1 \mathrm{~m}$ de profundidade. $O$ horizonte $C$ não é bem marcado como a passagem de $A$ para $B$, ocorre próximo a $1 \mathrm{~m}$ e é gradacionalmente rápido, trata-se de sedimento argilo arenoso de coloração amarela. Não se sabe até que profundidade vai esse horizonte.

\section{Metodologia}

O método magnético é sensível as propriedades magnéticas da cerâmica bem como rochas magnéticas. O GPR, por sua vez permite ver o contraste entre elementos, como é o caso da diferença entre solo e cerâmica e, especialmente, os espaços "vazios" das urnas-ossos, bem como a raízes.

O sítio, em terreno sedimentar, devido à presença de árvores frondosas, é rico em raízes, detectadas pelo GPR. Por outro lado, possui rochas magnéticas esparsas, provavelmente trazidas por ocasião da construção da fundação da casa que são magnéticas, logo detectáveis pela magnetometria bem como possuem um contraste nas propriedades eletromagnéticas considerável, sendo, portanto, também detectáveis pelo GPR, há, contudo, diferenças importantes entre urnas e as rochas magnéticas: as urnas, a menor recuperada possui diâmetro de $22 \mathrm{~cm}$ e altura 10 e a maior, cerca de $75 \mathrm{~cm}$ e altura 35, enquanto as amostras de rochas magnéticas possuem dimensões de $10 \times 10 \times 10 \mathrm{~cm}$; além disso, o contraste nas propriedades físicas produzido pelas rochas magnéticas é muito superior ao das urnas, conseqüentemente, seria possível eliminar dos resultados do GPR aqueles produzidos por raízes, bem como tentar separar aqueles produzidos pelas rochas magnéticas.

Foram demarcadas três áreas para os trabalhos, sendo que a área 1 com $10 \times 40 \mathrm{~m}$ possui urnas aflorantes e poucas raízes aflorates, e a área 2 vizinha, pode ou não conter urnas em subsuperfície, possui algumas raízes aflorantes, e a área 3-Base, de $4 \times 4 \mathrm{~m}$, menor do que as demais, contendo urnas e raízes, para testes diversos que deverão auxiliar a investigação nas demais áreas.. Os trabalhos foram realizados nos dias 19 a 23 de junho de 2010, acompanhando a equipe do LAANF, que recuperou mais uma urna da área 1 . Os dados apresentados neste trabalho envolvem somente a área 3. Esta área localiza-se a sudeste da casa do sitio próximo a região de árvores de grande porte (figura 1C), Antes de começar a utilizar os métodos, levantou-se a localização e medidas da borda superior de cada uma das duas urnas aflorantes (figura 2) bem como a posição das raízes visíveis. A urna 1 tem $75 \mathrm{~cm}$ de diâmetro e a urna $2,50 \mathrm{~cm}$. 
Silveira ${ }^{* 1}\left(\right.$ UFPA), Silva ${ }^{2}$ (UFPA), Nogueira ${ }^{3}\left(\right.$ UFPA), Brasil ${ }^{4}($ UFPA)

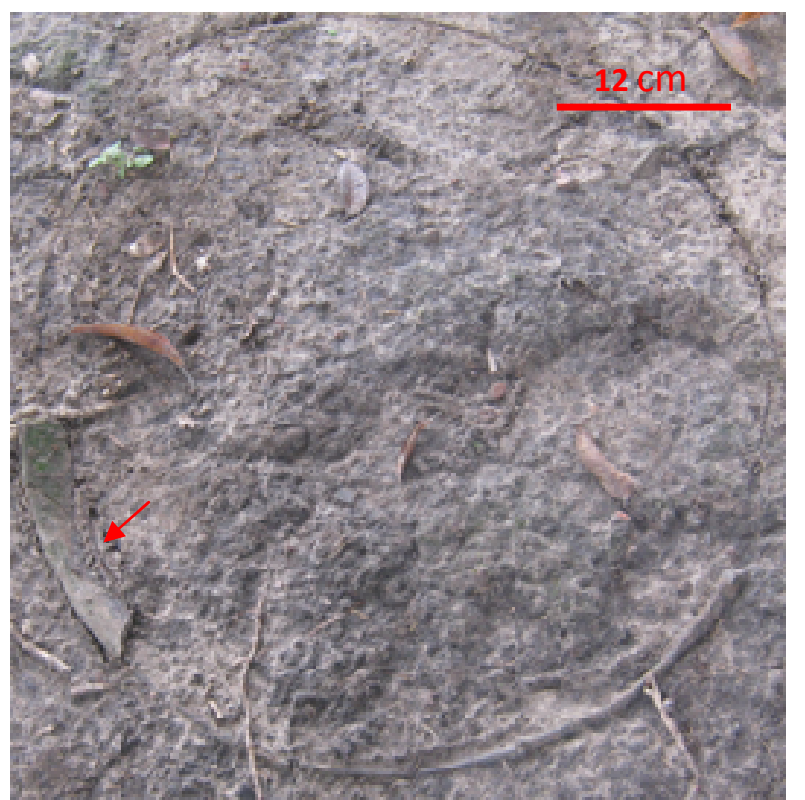

Figura 2- Borda de urna aflorante, Seta vermelha indica a borda.

O primeiro método a ser utilizado foi o GPR. O equipamento utilizado foi o GSSI, modelo SIR-SYSTEM 3000 , com uma antena monoestática de $400 \mathrm{MHz}$.

Perfis Leste-Oeste foram marcados com auxílio de trena espaçados de $0,25 \mathrm{~m}$ (figura 3 ), totalizando 20 perfis. $O$ levantamento com o GPR foi feito da Leste para oeste com marcas para interpolação do início $(0 \mathrm{~m})$, centro e final $(4 \mathrm{~m})$ do perfil.

Para obtenção da velocidade foi enterrado corpo contrastante (pé de cabra) à uma profundidade adequada (neste caso $30 \mathrm{~cm}$ ) e através de software (neste caso reflex) tentar coincidir o topo da hipérbole com a altura adequada e obter uma velocidade ideal.

Em posse dos radargrama, foi feita a correção estática e correção hipérbole para que o seu topo coincidisse com uma altura de $30 \mathrm{~cm}$. Os testes indicam uma velocidade de onda de 0,085 ns que será usada em posteriores avaliações de outros radargramas.

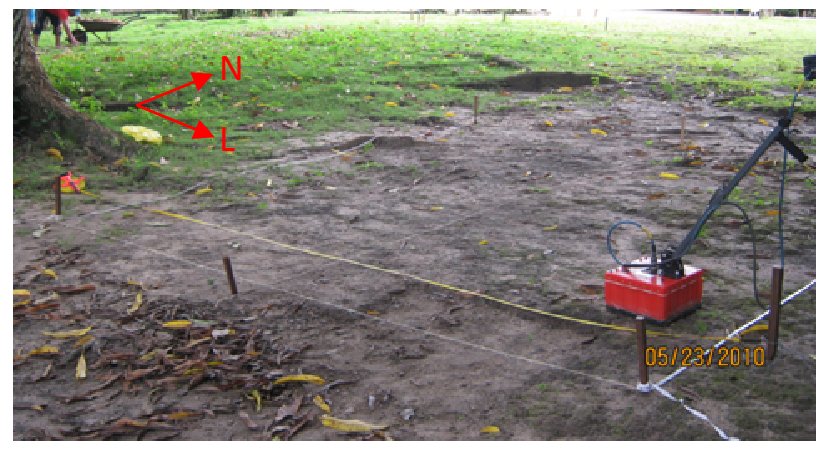

Figura 3 - Área preparada para o levantamento GPR. Equipamento GPR estacionado à direita.
Para o levantamento magnetométrico, foi imposta uma malha eqüidistante com $0,50 \mathrm{~m}$ de espaçamento sobre a anterior com o auxílio de barbante, (figura 4).

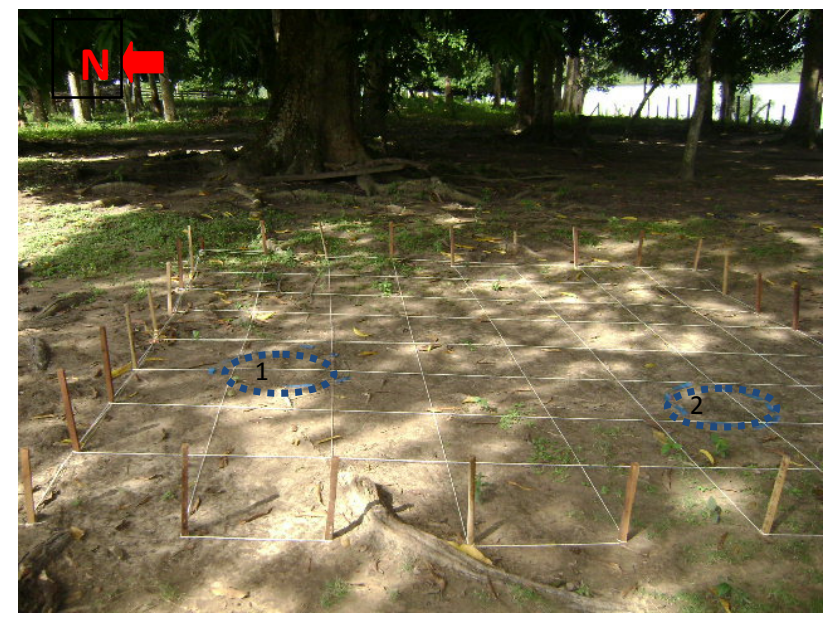

Figura 4- Malha para o levantamento magnetométrico. Em azul, as urnas aflorantes (1 e 2).

O levantamento magnetométrico foi realizado com um magnetômetro de precessão de prótons da Geotest, modelo M50A nos 83 pontos da malha (81 da malha e 2 adicionais). Foram realizadas umas poucas medidas adicionais no centro de cada urna bem como em suas proximidades. Como o contraste entre a susceptibilidade magnética da cerâmica e do terreno é muito pequeno, as medidas foram feitas com o sensor posicionado diretamente sobre 0 terreno. Foram tomadas regularmente medidas em uma área representativa do background local não afetada por contrastes magnéticos, para serem usadas na correção da variação diurna.. Os horário para a realização dos trabalhos era preferencialmente antes das 11:00 horas da manhã e depois das 14:00 horas da tarde, para evitar o pico da solar. Pelos dados da EMBRACE (estudo e monitoramento do clima espacial) o índice DST (índice geomagnético que mede o desenvolvimento temporal e intensidade de tempestades magnéticas) durante 0 período de maio de 2010 (as medidas foram executadas no dia 21 e 22 de maio) houve alterações fortes somente no início e fim do mês (figura 5)

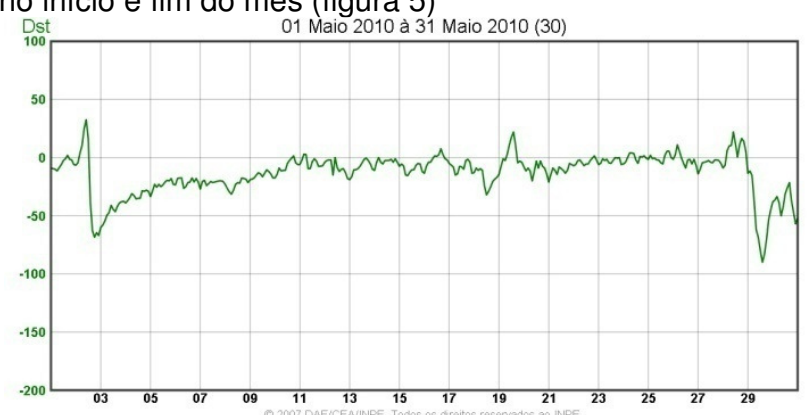

Figura 5 - Índice Dst em tempo real de Kyoto calculado pelo World Data Centre for Geomagnetism (WDC-C2), Kyoto, Japão 


\section{Resultados}

\section{GPR}

Os 17 radargramas de $4 \mathrm{~m}$ de extensão foram obtidos para uma profundidade de cerca de $2 \mathrm{~m}$.

Foram encontrados 3 tipos de feições . A primeira feição são hipérboles fortes bem formadas e de ampla abertura, provocados por raízes de grande porte (figura 6A). A segunda feição são hipérboles pequenas, pouco formadas e pouco abertas que foram associadas a raízes menores (figura 6B). A terceira feição são feições contínuas paralelas horizontalizadas com contraste maior do que o normal, associadas as urnas, mas especificamente a sua base (figura 7).

Os primeiros $10 \mathrm{~cm}$ do radargrama praticamente foram reduzidos visualmente por ondas diretas perdendo-se parte da superfície da urna.

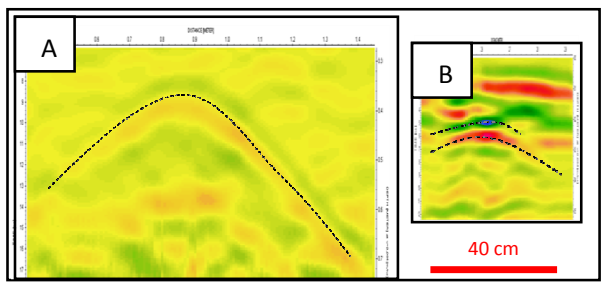

Figura 6 - Em A padrão de hipérbole para grandes raízes e em $B$ padrão para pequenas raízes.

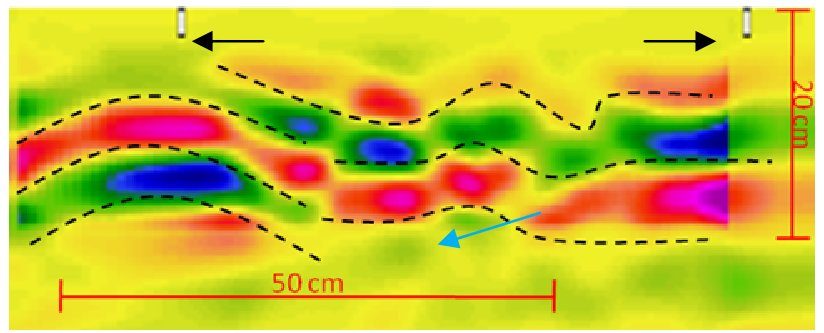

Figura 7 - Típica anomalia associada as urnas da área 3 ,setas pretas indicando as bordas e seta azul indicando a possível base.

Imagens 3D foram geradas através da interpolação dos radargramas. Nas imagens 3D, na posição das urnas observadas no terreno aparecem manchas de maior contraste do que a circunvizinhança (figura 8) que são seguidas ao longo das profundidades compatíveis com a altura das urnas (figura 9). A figura, obtida a $16 \mathrm{~cm}$ de profundidade, mostra as duas urnas de topo aflorante bem como uma possível terceira urna não aflorante (urna 3)

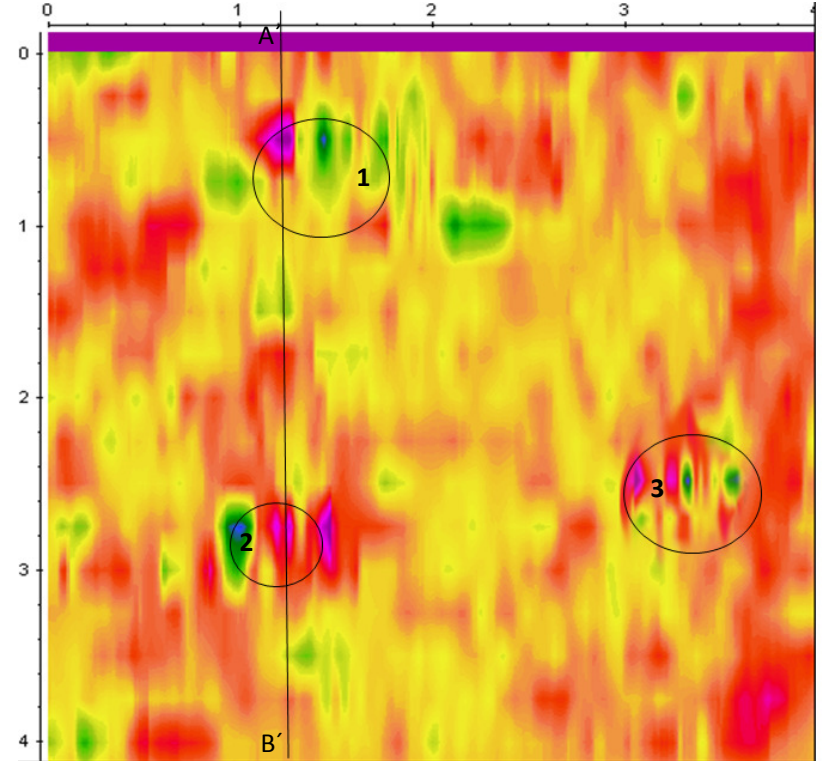

Figura 8 - Imagem 3D da área 3 a $16 \mathrm{~cm}$ de profundidade de $16 \mathrm{~cm} .1$ e 2 indicam as urnas de borda aflorante. 3 mostra a localizacao de uma provável terceira urna.

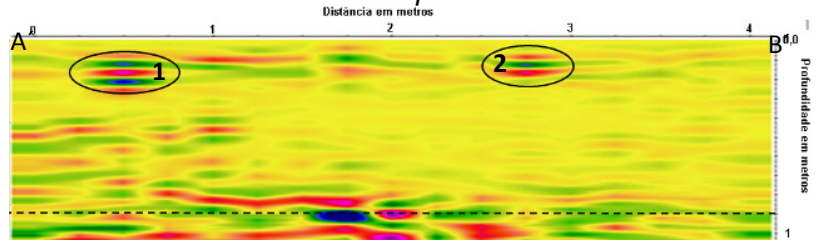

Figura 9 - Radargrama pelo perfil $A^{\prime} B,^{\prime}$ mostrando as urnas 1 e 2 . A linha tracejada aproximadamente a $1 \mathrm{~m}$ mostra passagem litológica do solo areno-argiloso para solo argiloso.

\section{Magnetometria}

As medidas magnéticas foram corrigidas da variação diurna lançadas sob a forma de mapa de isocontornos magnéticos (figura 10). As urnas aparecem nas imediações de baixo bem como alto magnéticos assim como observado por Aragão (2006) para alvos análogos. Aragão (2006) observou que urnas associadas a restos de esqueletos mostrava baixos magnéticos isolados, como a lógica permite crer que as urnas são transportadas para uma posição diferente pós cozimento, seu campo naturalmente não estará alinhado como campo terrestre que the deu origem, formando assim baixos magnéticos isolados como da urna 1 e altos magnéticos isolados como na urna 2. $\mathrm{O}$ alto magnético na coordenada $x=1$ e $y=3$, muito acima dos demais é provocado pela presença de rocha ígneas transportadas como na anomalia A(figura 12). 


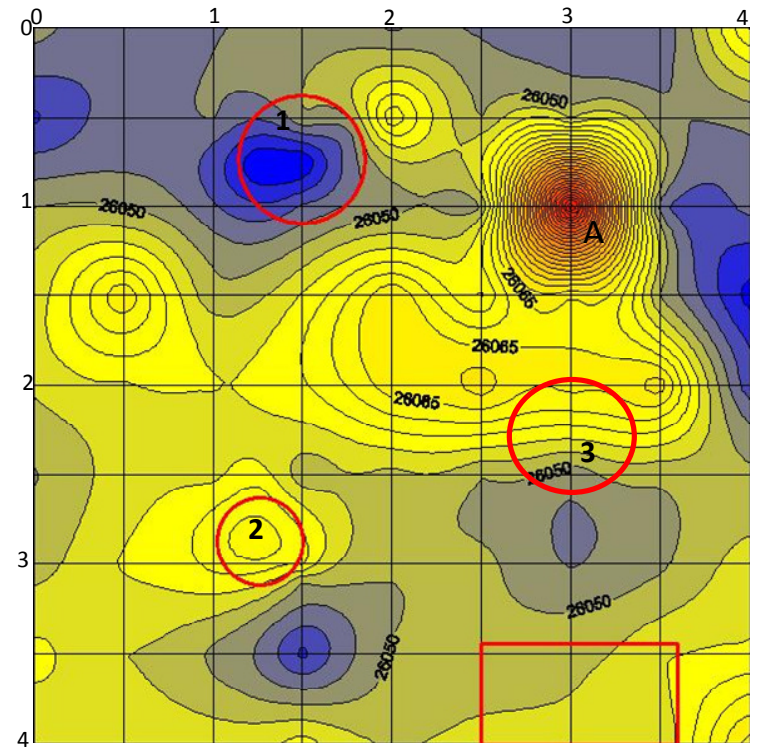

Figura 10 - Mapa de isocontornos magnéticos da área 3. 1 e 2 urnas. 3 possível urna mostrada pelo GPR. Altos magnéticos em amarelo, baixos em azul. $E$ em $\boldsymbol{A}$ anomalia provocada por rocha magnética.

\section{Discussão e Conclusões}

$\mathrm{Na}$ área, é comum nos 30 primeiros centímetros à ocorrência de raízes. É conhecido que raízes geram hipérboles nos radargramas, que podem ser confundidas com aquelas esperadas para os alvos. Na área 3 é possível separar hipérboles produzidas por raízes de manchas geradas por urnas, no 3D as urnas aparece como manchas (rever figura 08) em contraste a continuidade das raízes (figura 11).

\section{Agradecimentos}

Agradeço a equipe de Arqueologia do LAANF e a professora Denise Schaan responsáveis por toda organização da viagem e apoio financeiro e em especial à Ivone Bezerra pelo apoio pessoal.

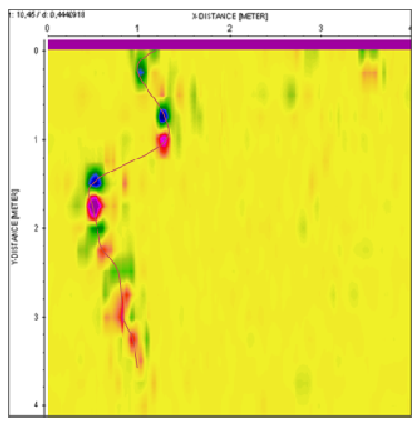

Figura 11 - Feição 3d superior de feição continua gerada por raiz

O procedimento de individualização não é fácil de notar quando as raízes diminuem, diminuindo assim a hipérboles. Além disso, as urnas estão muito próximas à superfície, gerando hipérboles muito próximas da zona da resposta das ondas diretas. Antenas de maior freqüência são, certamente, mais indicadas, pois facilitariam seja diferençar hipérboles de diferentes origens, como observar alvos tão rasos como os da área. O trabalho com o GPR permite, portanto, a obtenção de resultados úteis apesar da superficialidade das urnas. No caso, contudo, em que raízes aparecem de forma abundante, a passagem do equipamento, caso de alguns locais do sítio arqueológico sob investigação, na forma tradicional é inviável. . Nesses casos, a Magnetometria pode apontar as posições para as escavações.As rochas ígneas que foram inseridas na região por ação antrópica se tornam o principal ruído, com anomalias magnéticas acima do comum (5 a 10 vezes acima do background), , tornando fácil a sua separação das anomalias muito pequenas, no máximo 2 a 3 vezes acima do background, provocadas pelas urnas, sendo, portanto, mais indicado o emprego de outros tipos de, equipamentos para se trabalhar mais distante da faixa de ruído da área, caso dos gradiômetros.

\section{Referências Bibliográficas}

- $\quad$ ALVES, J.J.A. 1979. Métodos Geofísicos Aplicados à Arqueologia no Estado do Pará. Belém. Universidade Federal do Pará: 55p. (Dissertação de Mestrado)

- ALVES \& LOURENÇO, J.S. 1981. Métodos Geofísicos Aplicados à Arqueologia no Estado do Pará. Boletim do Museu Paraense Emílio Goeldi, Série Geologia, 26: 1-52.

- FUNARI, P. P. Arqueologia. São Paulo: Contexto, 2003.

- NEVES, E. G. Arqueologia da Amazônia. Rio de Janeiro: Jorge Zahar Editor, 2006. 86 p. 
- ROOSEVELT, A.C. 1991. Moundbuilders of the Amazon: Geophysical Archaeology on Marajo Island, Brazil. San Diego: Academic Press: 495.

- LUIZ, J. G. . Levantamento Geofísico no Sítio Arqueológico JK, Município de Acrelândia - Acre. 2010.

- LUIZ, J. G. . Prospecção Arqueológica através de Medidas Geofísicas Magnéticas e Georadar no Sítio PA-BA-84:Alunorte. 2006

- PEREIRA, Edithe ; GUAPINDAIA, Vera ; LUIZ, J. G. . Levantamento Arqueológico na Área da Sub-Estação Santa Rita, Macapá (AP). 2004.

- LUIZ, J. G. . Prospecção Arqueológica Através de Medidas Magnéticas e Georadar na Porção Norte da Parte Oeste e na Parte Leste do Sítio Domingos, Canaã dos Carajás-PA. 2004.

- LUIZ, J. G. . Prospecção arqueológica através de medidas geofísicas magnéticas e elétricas no Sítio Domingos, Canaã dos Carajás - PA. 2003.

- LUIZ, J. G. . Metodologias Geofísicas Aplicadas à Prospecção Arqueológica no Estado do Pará. In: Edithe da Silva Pereira; Vera Lúcia Calandrini
Guapindaia. (Org.). Arqueologia Amazônica. Belém: , 2010, v. 2

- LUIZ, J. G. . Contribuição da Geofísica para o Salvamento Arqueológico. In: Paulo Roberto do Canto Lopes; Maria Ivete Herculano do Nascimento. (Org.). Cadernos da Pesca: Informes de Pesquisa - Salvamento Arqueológico do Programa de Arqueologia Preventiva na Área de Influência da Mina de Bauxita Paragominas (Barcarena, Abaetetuba e Moju). 1 ed. Belém: MPEG; VALE, 2009, v. 3, p. 39-46

- MELO, M.S; Geofísica aplicada à arqueologia: investigação no sítio histórico engenho Murutucu, em Belém, Pará - Dissertação (Mestrado em Geofísica) - Universidade Federal do Pará, Instituto de Geociências, 2007

- ARAGÃO, R. C. Metodologia Geofísica aplicada à pesquisa de salvamento arqueológico nos Sítios Bittencourt, Jambuaçu e Jaburu, Estado do Pará. 2006. 60 f. Dissertação (Mestrado em Geofísica) - Universidade Federal do Pará, Belém, 2006. 